\title{
Burden by chronic diseases and disability and nursing care situation of seniors in Germany up to 2015
}

\section{Doris Bardehle* \\ Foundation of Men's Health, Coordinator of the Scientific Board, Claire-Waldoff-Street 3, 10117 Berlin, Germany}

\section{Issue/problem}

In a previous publication [1] the subjective health of male seniors was analysed up to the year 2013. 52\% of seniors in Germany rated their health as "very good" and "good". But how is the health of the other half of the male population $65+$ ? Could it be that a bias is present, because only part of the elderly population is reached, due to the fact that many of them are not included in interviews because of dementia and need for care.

\section{Description of the problem}

Previous analyses of the health status of male seniors 65+ were based on data up to 2013. Now we want to analyse current official statistical data and health reports by 2015/2016 and try to follow the further development of the health situation of male seniors. The analysis also includes new data sources, such as the population projection up to 2060 [2], the nursing care statistics [3], and the survey of "Older people in Germany and the European Union" [4].

The Third Men's Health Report of the Men's Health Foundation [5] highlighted the close link between the sexuality of men of different age groups and chronic diseases and disabilities that have a significant impact on quality of life.

Data on hospital morbidity, severely disabled persons, care situation and mortality are published by the Federal Statistical Office Germany, Department of Health Statistics and the Department of Population Statistics. Morbidity and mortality data are stratified by gender and age.

\section{Methods}

The analysis of the health situation of seniors $65+$ is based on published health records and on official statistics. Since the previous publication [1] which provided data up to 2013, the present analysis was based on data from 2015. Some statistical series have published updated data. Other sources have been included for the first time in the analysis.

a) Men's health reports: Third German Men's Health Report of the Men's Health Foundation Berlin, 2017 [5],

b) Publication of the Robert Koch-Institute: Robert Koch-Institute: Center for Cancer Registry Data (ZfKD). Report on cancer in Germany 2016. http://www.krebsdaten.de downloaded 14.08.2017 [6]

c) Publications of the Federal Statistical Office Germany

Statistical Yearbook Germany, 2015, Population and Demography (Statistisches Jahrbuch Deutschland, 2015, Bevölkerung und Demography) [7]
Population of Germany up to 2060. Results of the 13. Coordinated population pre-calculation for Germany 2015 (Koordinierte Bevölkerungsvorausberechnung für Deutschland bis zum Jahr 2060 [2],

Hospital-discharge Statistics 2015 (Diagnosedaten der Patienten in Krankenhäusern) [8]

Operations and Procedures of inpatient persons 2015 (Vollstationäre Patienten in Krankenhäusern. Operationen und Prozeduren (OPS Version 2015) [9].

Statistics of Severely Disabled Persons at 31.12.2015 (Schwerbehinderte Menschen am 31.12.2015) [10].

Care Statistics - Care within the framework of long-term care insurance 2015, (Pflege im Rahmen der Pflegeversicherung, Ländervergleich der Pflegeheime, 2015) [3],

Accidents, Violence, Self-harm 2015. (Unfälle, Gewalt, Selbstverletzung) [11].

Causes of Death Statistics, 2015. (Todesursachen in Deutschland 2015) [12].

\section{Results}

The population in Germany in 2015 and the prognostic development of the 65+ population by 2060

$82,175,700$ people, 40,514,100 men and 41,661,600 women lived in Germany at the end of the 2015. The increase in the population compared with previous years is due to migrants and the reception of refugees. At the age of $65+, 17,300,200$ people lived. The average age of men was 42.8 years old and of women 45.6 years old. Life expectancy for 2013/2015 was 78.18 years for men and 83.06 years for women [7]. The further life expectancy of 65-year-old men was 17.71 years, of 80 -year-old men 7.81 years. The further life expectancy of 65 -year-old women was 20.90 years, of 80 -year-old women 9.30 years. The highest proportion of seniors $65+$ in the population is found in Italy, Germany and Greece with over $21 \%$, while Ireland, Slovakia, Luxembourg and Cyprus have the lowest proportion of seniors $65+$ with less than 15\%. The EU average in 2015 is $18.9 \%$ for seniors 65+ [4].

Correspondence to: Prof. Dr. sc. med. Doris Bardehle, Foundation of Men's Health, Coordinator of the Scientific Board, Claire-Waldoff-Street 3, 10117 Berlin, Germany, Tel: 49306521260; E-mail: bardehle@stiftung-maennergesundheit.de

Received: August 27, 2017; Accepted: September 19, 2017; Published: September 22, 2017 
The population structure is the basis for prognostic calculations in order to observe the distribution between children, adults and retirees. Population pre-calculations are carried out, which are checked periodically and corrected if necessary. The 13th population estimation for Germany up to the year 2060 is based on the data of the last census in 2011 and the population on December 31, 2013 [2]. The calculations were made in 8 variants and with three model calculations. A birth rate of 1.4 children per woman will continue to be assumed in the future. The life expectancy of men is assumed to be 86.7 years in 2060 and the life expectancy of women up to this date is assumed to be 90.4 years [variant 2 of the forecast].

This means an increase in life expectancy of 9 years for men and 7.6 years for women from 2013 to 2060 . Men aged 65 can thus still live for 22 and women aged 65 can still live 25 years. This corresponds to 4 additional years of life compared with the 2013 population level (Figure 1).

The population grows upwards and widens, while the base of the younger population becomes narrower. In the initial year 2013, the share of 0-19 year olds was $18 \%$, the share of 20-64 year olds $61 \%$ and the share of $65+$ year olds $21 \%$. By 2060, the proportion of under 20 -year-olds will fall to $16 \%$, the proportion of 20-64 year-olds to 51 $52 \%$ and the proportion of $65+$ year-olds will increase to 32 to $33 \%$.

There will be twice as many 70 -year-olds in 2060 as children are born. The number of over 80 -year-olds will rise from the current 4.4 million to over 8 million. The working population will decline from 49 million to 38 million by 2060 , a decline of $23 \%$ [2].

An increase in the birth rate to at least 1.6 children per woman and a positive immigration rate of 200,000 to 300,000 migrants per year can significantly improve the situation but do not stop it. An annual migration of 300,000 people means a population gain of 14.5 million people by the year 2060 [2].

\section{Reflecting the health situation of seniors in official statistics Hospital-Discharge-Statistics and operations and procedures of inpatient persons, 2015}

According to the diagnosis data from patients in hospitals [8], a total of $19,758,261$ patients were hospitalized in 2015 , of whom $9,403,478$ were men and 10,354,778 women. Since 2005, this is equivalent to an increase of inpatient treatments of $19 \%$ for men and $14 \%$ for women. In 2015, 55 million operations and procedures were performed during in-patient treatment [9], including 16.4 million operations for men and women, with an operating rate of $83 \%$. While an average of $23.4 \%$ of the male and $24.9 \%$ of the female population received inpatient treatment during the course of 2015 (repeated inpatient treatment of the same person are counted), the use of hospitals increased steadily with increasing age (Table 1 ).

The treatment rates (per 100,000 of the corresponding age group and in \%) are higher for all age groups for men over 65 years than for women over 65 years [8]. The increase ranges from $37.7 \%$ for men aged 65-69 to $89.4 \%$ for men aged over 90 . On average, we observe that one in every 2. men aged over 65 years in 2015 was in inpatient treatment (53\%).

3,371,342 surgeries were performed in 2015 for men older than 65 years, on average $45 \%$ of inpatients (Table 2). This rate is higher than that of over 65 -year-old women with $36.4 \%$. In every age group of over 65 -year-old men, the quota of inpatient surgeries is higher than that of women [9].

\section{am 31.12.2013 und am 31.12.2060}

Variante 1: Kontinuität bei schwächerer Zuwanderung

am 31.12.2013

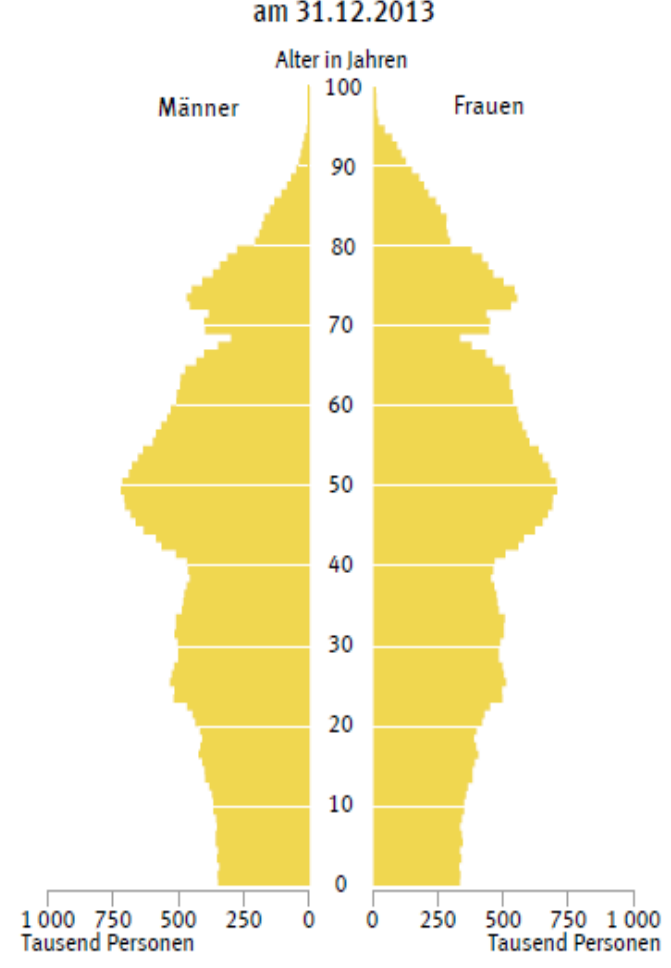

Variante 2: Kontinuität bei stärkerer Zuwanderung

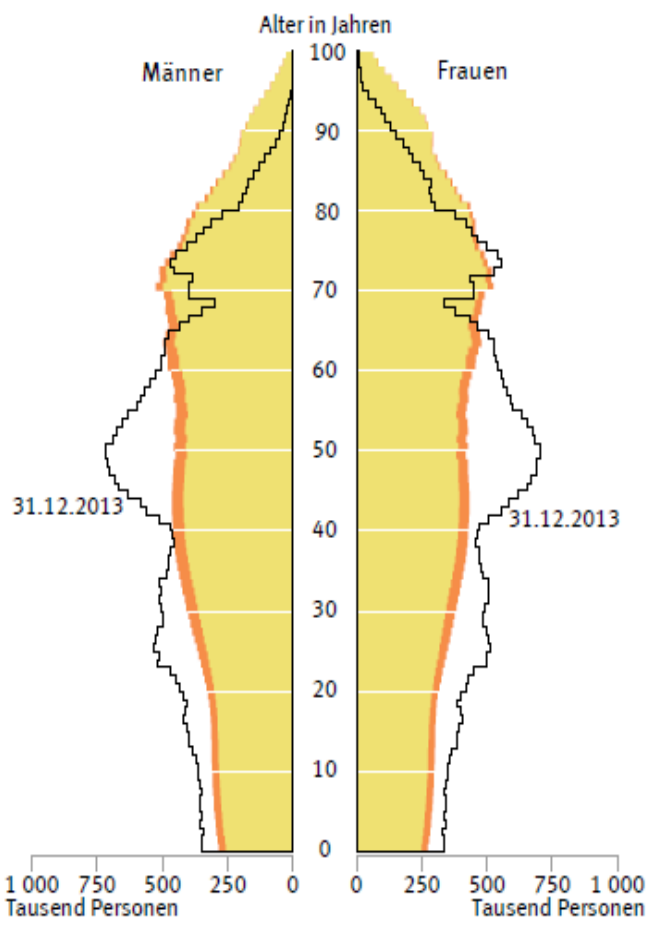

$2015 \cdot 15 \cdot 0381$

Figure 1. Population structure (population pyramids) 2013 and 2060 (Source: Federal Office of Statistics. Population of Germany up to 2060 [2]) 
Table 1. Hospital treatments by age, sex and rate, Germany, 2015

\begin{tabular}{|c|c|c|c|c|c|c|c|}
\hline \multirow{2}{*}{$\begin{array}{c}\text { Age from -- up to } \\
\text { years }\end{array}$} & \multirow{2}{*}{ Total } & \multicolumn{3}{|r|}{ Males } & \multicolumn{3}{|r|}{ Females } \\
\hline & & Total & per 100,000 & "rate in $\%$ & Total & per 100,000 & "rate in \% \\
\hline all ages of which & $1,97,58,256$ & $94,03,478$ & $23,210.37$ & 23.4 & $1,03,54,778$ & $24,854.51$ & 24.90 \\
\hline $65-69$ & $13,90,600$ & $7,56,001$ & $37,740.58$ & 37.7 & $6,34,599$ & $29,281.38$ & 29.3 \\
\hline $70-74$ & $17,98,610$ & $9,44,054$ & $48,323.41$ & 48.3 & $8,54,556$ & $38,080.32$ & 38.1 \\
\hline $75-79$ & $22,15,730$ & $10,89,071$ & $58,850.02$ & 58.9 & $11,26,659$ & $48,168.09$ & 48.2 \\
\hline $80-84$ & $15,76,697$ & $6,91,982$ & $70,088.60$ & 70.1 & $8,84,715$ & $60,051.43$ & 60.1 \\
\hline $85-89$ & $10,82,387$ & $3,99,220$ & $81,127.10$ & 81.1 & $6,83,167$ & $69,686.17$ & 69.7 \\
\hline $90+$ & $5,39,981$ & $1,40,867$ & $89,354.83$ & 89.4 & $3,99,114$ & $73,083.34$ & 73.1 \\
\hline Total 65+ & $86,04,005$ & $40,21,195$ & $53,579.92$ & 53.6 & $45,82,810$ & $46,786.58$ & 46.8 \\
\hline
\end{tabular}

"rate in \%: Percentag of inpatient operations in relation to the corresponding population.

Source: ${ }^{\circ}$ Federal Statistical Office. Diagnostic data of patients in hospitals, Germany [4], 2015. Own calculations.

Table 2. Hospital operations performed by age, sex and rate, Germany, 2015

\begin{tabular}{|c|c|c|c|c|c|c|c|}
\hline \multirow{2}{*}{$\begin{array}{c}\text { Age from -- up to } \\
\text { years }\end{array}$} & \multirow{2}{*}{ Total } & \multicolumn{3}{|c|}{ Males } & \multicolumn{3}{|c|}{ Females } \\
\hline & & total & per 100,000 & "rate in \% & total & per 100,000 & "rate in $\%$ \\
\hline all ages of which & $1,64,22,693$ & $78,26,781$ & $19,481.82$ & 19.5 & $85,95,727$ & $20,706.70$ & 20.7 \\
\hline $65-69$ & $14,03,142$ & $7,37,147$ & $36,799.46$ & 36.8 & $6,65,980$ & $30,729.35$ & 30.7 \\
\hline $70-74$ & $17,23,831$ & $8,84,790$ & $45,289.86$ & 45.3 & $8,39,030$ & $37,388.46$ & 37.4 \\
\hline $75-79$ & $18,97,323$ & $9,36,402$ & $50,600.27$ & 50.6 & $9,60,903$ & $41,081.52$ & 41.1 \\
\hline $80-84$ & $11,00,809$ & $5,09,700$ & $51,625.85$ & 51.6 & $5,91,091$ & $40,121.24$ & 40.1 \\
\hline $85-89$ & $5,85,415$ & $2,37,529$ & $48,269.23$ & 48.3 & $3,47,874$ & $35,418.92$ & 35.5 \\
\hline $90+$ & $2,25,267$ & 65,774 & $41,721.80$ & 41.7 & $1,59,486$ & $29,204.11$ & 29.2 \\
\hline Total $65+$ & $69,35,787$ & $33,71,342$ & $44,921.03$ & 44.9 & $35,64,364$ & $36,389.12$ & 36.4 \\
\hline
\end{tabular}

"rate in \%: Percentag of inpatient operations in relation to the corresponding population

Source: ${ }^{\circ}$ Federal Statistical Office. Operations and Procedures of inpatient persons, Germany [5], 2015. Own calculations.

Which operations are performed particularly frequently in men aged $65+$ years? For example, there are 301.823 operations on the eyes, which correspond to $60 \%$ of all eye operations. Of 279,072 heart surgeries, 189,840 are performed representing $60 \%$ in men aged $65+$. $50 \%$ of the in-patient treated men $65+$ were operated on due to diseases of the digestive tract or the genital organs.

Considering that only $18.5 \%$ of the male population is aged $65+$, we also have increased rates in men for operations on the digestive tract and sexual organs. In the case of musculoskeletal disorders, $33 \%$ of men $65+$ undergo operations $(708,606)$ (a total of $2,161,077$ operations were performed for all ages) [9].

\section{Severely disabled persons, Germany, 2015}

The severely handicapped statistics were historically developed after the First World War for the social and financial protection of war invalids. Added later were handicaps by congenital malformations, blindness and dove, disabilities after accidents and illness sequences.

The severely disabled statistics do not yet follow the ICD-10 categories or the ICF, the International Classification of Functioning, Disability and Health. The statistics include persons with a disability rating of between 50 and 100 and with a disability certificate. Congenital disabilities, illnesses, accidents, injuries, damage caused by military service and civilian service are regarded as causes of disabilities.

The traditionally grown structure of severely handicapped persons is subdivided according to the type of handicap such as: loss or functional limitations of arms and legs, functional limitations of the spine or trunk, blindness/visual impairment, speech/speech disorders, loss of one or both breasts, impairment of the function of internal organs, paraplegia/cerebral disorders/spiritual and mental handicaps, addictive diseases, other or inadequately described disabilities [10].

On 31 December 2015,7.6 million people were severely disabled, or $9.3 \%$ of the population. The proportion of men predominates with
$51 \%$. The share of severely disabled men aged 65 and over was $53 \%$ for men and $57 \%$ for women because of their higher life expectancy [10].

Available data by age, sex and causes of the severely disabled indicate that mainly general diseases and multiple causes lead to severe disability (Table 3). $96 \%$ of severely disabled male seniors are in these two groups, and $98 \%$ of women. Congenital disabilities, the consequences of accidents and recognised war injuries all affect $4 \%$ in men and $2 \%$ in women. Based on 100,000 men 65+, 27,620 severely disabled persons were identified at the end of 2015 , compared with 21,909 for women $65+$. This corresponds to $28 \%$ of men and $22 \%$ of women aged $65+$. Not all data on severe disability are gender-specific. Data by type of most severe disability are currently available for 2015 only for men and women as a whole (Table 4). The most frequent impairment of the function of internal organs is $28.65 \%$ in severely handicapped persons aged 65-74 years, with $75+$ years of age the proportion is $23.99 \%$.

Paraplegics are disabled people with a high level of care. At the end of 2015 , there were a total of 17,119 people with paraplegia/cerebral palsy, of whom 2,618 were aged 65-74 years and 2,376 were aged $75+$. Most of them have a disability grade of 100 [10].

923,308 men of all age groups had the highest grade of disability (100) and included 505,419 over 65-year-old men, which means that $55 \%$ of the severely disabled are older people with the highest degree of disability [10].

By comparison, in 2015 there were a total of 892,499 severely disabled women with a degree of disability of 100 , representing $64 \%$ of all severely disabled women with the highest degree of disability among the elderly [10].

\section{Long-term care of seniors 65 years and more, 2015}

Social nursing care insurance was introduced in 1994 as part of the social security legislation in Germany, accompanied by comprehensive statistics every two years. At the end of 2015, 2.9 million people in need 
Table 3. Severely disabled men and women over 65 years by causes of the most severe disability, Germany, 2015

\begin{tabular}{|c|c|c|c|c|c|c|}
\hline \multirow{2}{*}{ Cause } & \multicolumn{3}{|l|}{ Males 65+ } & \multicolumn{3}{|l|}{ Females $65+$} \\
\hline & Total & per 100,000 & in $\%$ & Total & per 100,000 & in $\%$ \\
\hline Congenital disabilities & 16,168 & 217.18 & 0.79 & 18,960 & 194.46 & 0.89 \\
\hline $\begin{array}{l}\text { Accident at work. } \\
\text { Occupational disease }\end{array}$ & 30,826 & 414.08 & 1.50 & 4,800 & 49.23 & 0.22 \\
\hline Traffic accident & 7,181 & 96.46 & 0.35 & 3,726 & 38.22 & 0.17 \\
\hline Domestic accident & 2,165 & 29.08 & 0.11 & 1,433 & 14.70 & 0.07 \\
\hline Another accident & 7,266 & 97.60 & 0.35 & 3,684 & 37.78 & 0.17 \\
\hline $\begin{array}{l}\text { Recognized war injury } \\
\text { and the like }\end{array}$ & 18,603 & 249.89 & 0.90 & 2,609 & 26.76 & 0.12 \\
\hline General diseases & $18,14,937$ & $24,379.94$ & 88.27 & $19,30,122$ & $19,795.99$ & 90.35 \\
\hline $\begin{array}{l}\text { Other and multiple } \\
\text { causes }\end{array}$ & $1,58,981$ & $2,135.58$ & 7.73 & $1,70,831$ & $1,752.10$ & 8.00 \\
\hline Total 65+ & $20,56,127$ & $27,619.83$ & $100 \%$ & $21,36,165$ & $21,909.24$ & $100 \%$ \\
\hline
\end{tabular}

In \%: Percentage of the disabled persons in relation to the corresponding popul. at age $65+$

Source: ${ }^{\circ}$ Federal Statistical office. Statistics of the Severely Disabled Persons at 31.12.2015 [7]. Own calculations.

Table 4. Severely disabled men and women 65-74 and 75 years and over by type of the most severe disability, Germany, 2015

\begin{tabular}{|c|c|c|c|c|c|c|}
\hline \multirow[b]{2}{*}{ Type of disability } & \multicolumn{3}{|c|}{ Males \& females $65-74$} & \multicolumn{3}{|c|}{ Males \& Females 75+ } \\
\hline & Total & per 100.000 & in $\%^{*}$ & Total & per 100.000 & in $\%{ }^{*}$ \\
\hline Loss/Partial loss of limbs & 12,772 & 152.63 & 0.74 & 22,514 & 255.08 & 0.91 \\
\hline Limitation of function of limbs & $2,37,952$ & $2,843.56$ & 13.78 & $4,27,431$ & $4,842.67$ & 17.34 \\
\hline Funktionseinschränkung Wirbelsäule, Brustkorb & $2,50,248$ & $2,990.50$ & 14.49 & $3,90,722$ & $4,426.76$ & 15.85 \\
\hline Blindness/visual impairment & 59,343 & 709.16 & 3.44 & $1,90,309$ & $2,156.14$ & 7.72 \\
\hline Speech disorders/deafness/balance disorders & 76,923 & 919.24 & 4.45 & $1,14,351$ & $1,295.56$ & 4.64 \\
\hline Loss of one/both breasts & 45,513 & 543.89 & 2.64 & 47,347 & 536.43 & 1.92 \\
\hline Impairment of the function of internal organs & $4,94,719$ & $5,911.97$ & 28.65 & $5,91,565$ & $6,702.26$ & 23.99 \\
\hline $\begin{array}{l}\text { Paraplegic persons/cerebral palsy, mental disorders, addictive } \\
\text { disorders }\end{array}$ & $2,56,798$ & $3,068.78$ & 14.87 & $3,04,246$ & $3,447.02$ & 12.34 \\
\hline Other disabilities & $2,92,493$ & $3,495.34$ & 16.94 & $3,77,046$ & $4,271.82$ & 15.29 \\
\hline Total & $17,26,761$ & $20,635.06$ & 100.00 & $24,65,531$ & $27,933.73$ & 100.00 \\
\hline
\end{tabular}

in \%: Percentage of all disabled persons in relation to the corresponding population $65+$

Source: ${ }^{\circ}$ Federal Statistical Office. Statistics of the Severly Disabled Persons at 31.12.2015 [7]. Own calculations.

Bev. M \& w 65-74 und 75+ 83,68,094 88,26,357

Schwerbeh m \& w 65-74 und 75+ 17,26,671 24,65,531

of care were included in the statistics [3]. The majority of these are women with a share of $64 \%$. Persons in need of care are persons who receive care insurance benefits in accordance with current legislation.

2.08 million people in need of care, or $73 \%$ of all those in need of care, are cared for at home either by relatives ( 1.38 million) or by employees of the 13,300 outpatient nursing services $(692,000$ people in need of care). In 13,600 nursing homes, 783,000 people in need of care are cared for [3].

$2 \%$ of the patients in need of care had limited everyday competence (dementia). Every 8. nursing case has cancer as the first diagnosis to establish nursing [6]. Compared with the statistical data from 2013, the number of people in need of care increased by $9 \%$ in 2015 , especially in the outpatient sector. The absolute increase in the number of people in need of care within 2 years was 234,000 . Compared to the statistical data of 2013, the increase was mainly due to the increase in the care level I $(+11.7 \%$, lower maintenance effort), followed by care level II $(+6.4 \%)$ and care level III $(+4.3 \%$ Maintenance effort $)$ [3]. The average age and the cost of care for those in need of care in nursing homes is higher than that of the citizens who are cared for at home. $51 \%$ of the residents of nursing homes are 85 years and older. Whereas "only" every 30th person in the 65-69 year olds (3.3\% for men and 3\% for women) was in need of care, the rate for men aged 90 and over was $53 \%$ for men and $70 \%$ for women (Table 5 ).
On average, $10 \%$ of men over 65 years of age and $16 \%$ of women over 65 years of age have a care level, but this is increasing almost exponentially among men and women over 85 years of age and reaches $70 \%$ for women over 90 years of age due to their higher life expectancy.

\section{Accidents, violence, self-harm of seniors 65+ in 2015}

Fatal injuries have increased in recent years, especially fatal accidents among seniors [11]. The data are not absolutely consistent with the cause of death statistics because they come from different data sources.

The increase in fatal accidents affects the elderly population in particular. Men have higher mortality rates than women. In particular, accidents are increasing among 85-year-olds and older men and women. The average fatal accident rate of seniors $(65+)$ is more than three times higher than the average rate across all age groups (Table 6). Deaths resulting from events of undetermined intent (Y10-Y34) concern 354 poisonings, drowning, undefined forms of hangings, accidents in men and 336 deaths among women of all ages [11]. This group of causes of death results from the fact that many seniors live alone and without relatives, so that the circumstances of death often cannot be fully clarified. Killing offences (Assaults: X85-Y09) play a minor role with 47 deaths among male senior citizens, the majority of these are killing offences among female senior citizens with 64 cases, and a total of 111 killing offences in 2015. The fatal 
Table 5. People in need of care by age, gender and quota, Germany, 2015

\begin{tabular}{|c|c|c|c|c|c|c|c|}
\hline \multirow{2}{*}{$\begin{array}{c}\text { Age from .... up to } \\
\text { years }\end{array}$} & \multirow{2}{*}{ Total } & \multicolumn{3}{|c|}{ Males } & \multicolumn{3}{|c|}{ Females } \\
\hline & & total & per 100,000 & "quota & total & per 100,000 & "quota \\
\hline all ages of which & $28,60,293$ & $10,28,434$ & $2,538.46$ & 2.5 & $18,31,859$ & $4,397.00$ & 4.4 \\
\hline $65-69$ & $1,36,976$ & 69,006 & $3,317.08$ & 3.3 & 67,970 & $3,018.79$ & 3.0 \\
\hline $70-74$ & $2,14,427$ & 99,749 & $5,399.51$ & 5.4 & $1,14,678$ & $5,404.69$ & 5.4 \\
\hline $75-79$ & $4,22,093$ & $1,72,154$ & $9,110.27$ & 9.1 & $2,49,939$ & $10,500.63$ & 10.5 \\
\hline $80-84$ & $5,33,737$ & $1,78,674$ & $17,526.05$ & 17.5 & $3,55,063$ & $23,593.24$ & 23.6 \\
\hline $85-89$ & $5,89,665$ & $1,57,866$ & $31,289.72$ & 31.3 & $4,31,799$ & $43,963.77$ & 44.0 \\
\hline $90+$ & $4,74,942$ & 87,503 & $53,462.41$ & 53.5 & $3,87,439$ & $69,881.98$ & 69.9 \\
\hline Total $65+$ & $23,71,840$ & $7,64,952$ & $10,192.51$ & 10.2 & $16,06,888$ & $16,404.96$ & 16.4 \\
\hline
\end{tabular}

"Quota: Percentage of people in need in care in relation to the corresponding population.

Source: ${ }^{\circ}$ Federal Statistical Office. Care Statistics, 2015. Own calculations [7].

accidents (V01-X59) among seniors have risen from 2010 to 2015, affecting all age groups (Table 7). Each subsequent age group from 65-69 years has a higher incidence rate in 2015 compared to 2010. High incidence increases are noticeable in men over the age of 80 . Deadly accidents include transport accidents, falls, exposure to mechanical forces, drowning, suffocation, exposure to smoke, fire and flames, natural forces, poisoning. In the period from 2010 to 2015, the age group of the 90 years and over experienced high suicide rates (Table 8).

Of 7,397 suicides in men, 2,715 were $65+$ in 2015 . These figures do not show any fundamental tendencies compared with 2010 . The $90+$ age group is striking, with suicides doubling since 2010 [11]. The validity of the information should be questioned.

\section{Mortality of seniors 65+, 2015}

In the cause-of-death statistics, all deceased persons are coded according to their underlying illness or external causes of death such as accidents, suicide or assault. In 2015,925,200 people died in Germany [12]. The number of deceased thus rose by $6.5 \%$ compared to the previous year. 449,512 men and 475,688 women died in 2015 .

As in previous years, the most common causes of death are cardiovascular diseases (157,996 men) and neoplasms (126,407 men), and diseases of the respiratory system (36,600 men) in third place. Only in fourth place are injuries, poisoning and other external causes in men with 21,591 deaths.

In malignant neoplasms of the digestive organs (C15-C26), the majority of deaths in men are 39,528 compared to 30,999 in women. 30,038 deaths resulting from neoplasm of the digestive organs in men, or $76 \%$, occur in the elderly.

Of 30,980 deaths in men as a result of malignant neoplasms of the respiratory and intrathoracic organs (C30-C39), 22,281 occur in the elderly age group, or $72 \%$. Of the 14,264 deaths due to malignant neoplasms of the male genital organs (C60-C63), 13,081 occur in the elderly, which corresponds to $92 \%$. In diabetes mellitus (E10-E14) a total of 10,871 deaths among men and 13,529 deaths among women were registered in 2015. 9,234 deaths due to diabetes in men, i.e., $85 \%$, were attributable to the age of $65+$.

The distribution of deaths by age groups (Table 9) shows a steady progressive increase of $1.8 \%$ in deaths among 65-69 year old men up to $26.2 \%$ in the age group $90+$. The death rates among male seniors are higher in all age groups than among female seniors. While the average mortality rate is $1.1 \%$ of the German population, it averages $4.8 \%$ for men in the $65+$ age group and $4.4 \%$ for women (Table 9 ).
Table 6. Fatal transport accidents and events of undetermined intent, Germany, 2015, (V01-Y34)

\begin{tabular}{|c|r|r|r|r|r|}
\hline \multirow{2}{*}{$\begin{array}{c}\text { Age from } \\
- \text { - up to years }\end{array}$} & \multirow{2}{*}{ Total } & \multicolumn{2}{|c|}{ Males } & \multicolumn{2}{c|}{ Females } \\
\cline { 3 - 6 } $\begin{array}{c}\text { all ages of } \\
\text { which }\end{array}$ & 34,445 & 20,513 & 50.6 & 13,932 & 33.4 \\
\hline $65-69$ & 1,549 & 1,061 & 51.0 & 488 & 21.6 \\
\hline $70-74$ & 2,396 & 1,605 & 86.9 & 791 & 37.3 \\
\hline $75-79$ & 3,685 & 2,255 & 119.3 & 1,430 & 60.1 \\
\hline $80-84$ & 4,290 & 2,297 & 225.3 & 1,993 & 132.4 \\
\hline $85-89$ & 5,039 & 2,199 & 435.9 & 2,840 & 289.2 \\
\hline $90+$ & 4,633 & 1,394 & 851.7 & 3,239 & 584.2 \\
\hline Total $65+$ & 21,592 & 10,811 & 144.0 & 10,781 & 110.1 \\
\hline
\end{tabular}

Source: ${ }^{\circ}$ Federal Statistical Office: Accidents, Violence, Self-harm, Germany. 2015 [3] Own calculations.

Table 7. Fatal accidents of seniors 65+, Germany, 2010 and 2015 (V01-X59)

\begin{tabular}{|c|r|r|r|r|}
\hline \multirow{2}{*}{$\begin{array}{c}\text { Age from -- up } \\
\text { to years }\end{array}$} & \multicolumn{2}{|c|}{ Males 2010 } & \multicolumn{2}{c|}{ Males 2015 } \\
\cline { 2 - 5 } & \multicolumn{1}{|c|}{ total } & per 100,000 & \multicolumn{1}{c|}{ total } & per 100,000 \\
\hline all ages of which & 10,098 & 25.20 & 12,083 & 30.10 \\
\hline $65-69$ & 672 & 30.20 & 590 & 29.50 \\
\hline $70-74$ & 953 & 42.70 & 942 & 48.20 \\
\hline $75-79$ & 1,027 & 75.30 & 1,484 & 80.20 \\
\hline $80-84$ & 1,264 & 146.00 & 1,706 & 172.80 \\
\hline $85-89$ & 975 & 264.40 & 1,784 & 362.50 \\
\hline $90+$ & 600 & 415.60 & 1,189 & 754.20 \\
\hline Total 65+ & 5,491 & 76.27 & 7,695 & 102.53 \\
\hline
\end{tabular}

Source: ${ }^{\circ}$ Federal Statistical Office. Accidents, violence, self-harm, Germany, 2015 [3]. Own calculations.

Table 8. Suicides of seniors 65+ by age, Germany, 2010 \& 2015 (X60-X84)

\begin{tabular}{|c|r|r|r|r|}
\hline \multirow{2}{*}{\begin{tabular}{c} 
Age from - $\begin{array}{c}|c| \\
\text { to years }\end{array}$ \\
\cline { 2 - 5 } Males 2010
\end{tabular}} & \multicolumn{2}{|c|}{ Males 2015 } \\
\hline all ages of which & \multicolumn{1}{|c|}{ total } & per 100,000 & \multicolumn{1}{c|}{ total } & per 100,000 \\
\hline $65-69$ & 7,465 & 18.60 & 7,397 & 18.40 \\
\hline $70-74$ & 543 & 24.40 & 406 & 20.30 \\
\hline $75-79$ & 632 & 28.30 & 580 & 29.70 \\
\hline $80-84$ & 478 & 35.00 & 681 & 36.80 \\
\hline $85-89$ & 420 & 48.50 & 517 & 52.40 \\
\hline $90+$ & 291 & 78.90 & 353 & 71.70 \\
\hline Total 65+ & 87 & 60.30 & 178 & 112.90 \\
\hline
\end{tabular}

Source: ${ }^{\circ}$ Federal Statistical Office. Accidents, Violence, Self-harm, Germany, 2015 [3]. Own calculations.

\section{Discussion}

For years now, Germany has been complaining of an ageing population with an increasing number of seniors, a too low birth rate and a declining number of people of working age. This was the reason for prognostic calculations and population policy measures [2]. 
Table 9. Deceased by age and sex 65+ and quota, Germany, 2015

\begin{tabular}{|c|c|c|c|c|c|c|c|}
\hline \multirow{2}{*}{$\begin{array}{c}\text { Age from -- up to } \\
\text { years }\end{array}$} & \multirow{2}{*}{ Total } & \multicolumn{3}{|c|}{ Males } & \multicolumn{3}{|c|}{ Females } \\
\hline & & total & per 100,000 & "quota & total & per 100,000 & "quota \\
\hline all ages of which & $9,25,200$ & $4,49,512$ & $1,109.52$ & 1.1 & $4,75,688$ & $1,141.79$ & 1.1 \\
\hline $65-69$ & 56,656 & 35,868 & $1,724.16$ & 1.8 & 20,788 & 923.27 & 1.0 \\
\hline $70-74$ & 87,833 & 53,937 & $2,919.66$ & 2.8 & 33,896 & $1,597.49$ & 1.5 \\
\hline $75-79$ & $1,39,965$ & 79,775 & $4,221.64$ & 4.3 & 60,190 & $2,528.75$ & 2.6 \\
\hline $80-84$ & $1,56,003$ & 77,504 & $7,602.33$ & 7.9 & 78,499 & $5,216.11$ & 5.3 \\
\hline $85-89$ & $1,76,006$ & 69,549 & $13,784.91$ & 14.1 & $1,06,457$ & $10,838.96$ & 10.9 \\
\hline $90+$ & $1,67,902$ & 41,318 & $25,244.39$ & 26.2 & $1,26,584$ & $22,831.83$ & 23.2 \\
\hline Total $65+$ & $7,84,365$ & $3,57,951$ & $4,769.47$ & 4.8 & $4,26,414$ & $4,353.32$ & 4.4 \\
\hline
\end{tabular}

"quota: Percentage of deceased by age groups in relation to the corresponding male and female popul.

Source: ${ }^{\circ}$ Federal Statistical Office. Causes of death, Germany, 2015 [13]. Own calculations.

Model calculations show a further increase in life expectancy for men to 86.7 years by 2060 and for women to 90.4 years. Positive immigration rates, especially of young migrants, can have a balancing effect on the population pyramid, but a growing number of senior citizens, including many people of high age $(80+)$, will still be living in Germany.

The statement that by 2060 there will be twice as many 70 -year-olds as children will be born and that the number of over-80s is expected to rise from the current figure of 4.4 million to 8 million, with the working-age population declining by up to $20 \%$ compared with the situation in $2013[2,4]$.

Since the influx of refugees and migrants occurred mainly in 2015 and 2016, a current population forecast could already give a slightly modified picture, but it will have little effect on the increase in the number of senior citizens. The European Union has already stated years ago that an extension of the life expectancy should be accompanied by an increase in the healthy life expectancy, thus without burdening chronic illnesses and disability.

But can this trend be seen from the available data on the health situation of seniors? Their health situation was attempted to present with the use of available data and analyses whether dynamic changes can be registered compared with the publication "Subjective health and burden of disease of seniors" [1].

Hospital treatments in all age groups of male seniors have risen to almost $90 \%$ in the $90+$ age group and surpass female seniors in all age groups [8]. Repeated in-patient admissions are possible with the steadily shortening length of stay, but nevertheless we have to deal with an increased in-patient morbidity of older men [8] (Table 1).

On average, every second male senior citizen in 2015 was treated in hospitals in all seniors' age groups. With increasing life expectancy, it can be assumed that in-patient treatment will continue to rise in an increasingly older male population and must be taken into account in hospital planning [4]. At present, there is no evidence that health promotion measures can reduce the inpatient morbidity of seniors.

The same picture can be seen for in-patient operations [9], which are carried out in an average of $45 \%$ of all in-patient stays with seniors; they are more frequent in all age groups than with women (Table 2). Surgery in men go up to a high age (80-84 years) and then slightly decreases.

Surgery on the eyes of men 65+ with 301.823 interventions takes the first place of all surgical procedures, although eye surgery is performed additionally on an outpatient basis, which is not included here. Cardiac operations follow, $60 \%$ of which are performed in the elderly. Other operations, such as on the digestive tract or the sexual organs, are also 3 to 4 times more frequent in the elderly population.

It is also true for operations that there is an increase in the number of inpatient operations with an increasing ageing population and will continue to be in the future. Male seniors are more likely to undergo in-patient surgery than female seniors.

More than two million men $65+$ are severely disabled, which is about $28 \%$ of all seniors $65+$. Among women, $22 \%$ of senior citizens are severely disabled. Main causes of disability are "general diseases" (organic, mental), followed by recognized occupational diseases and the consequences of accidents at work and recognized war injuries [10]. This explains above all the difference to severely disabled female seniors (Table 3 ).

A list of types of disability (men and women could not be shown separately) shows that there is an increase in functional limitations of limbs and spine for male and female seniors $75+$ compared to the age group 65-74 years. (Table 4).

Particularly striking is the doubling of blindness and visual impairment from younger seniors to the $75+$ age group. This correlates with the eye operations that are so frequently performed in the hospital. If we recall that 1.7 million seniors in the 65-74 age group are severely handicapped, the number of 75 -year-olds and older people rises to 2.5 million. This corresponds to $28 \%$ of $75+$-year-olds and is almost one in three.

The number of paraplegic, mental disorders and addictive diseases among $75+$ year-olds increases to 304,246 . People who are attributed to this type of disability require almost all external help to cope with everyday life. The nursing care statistics, which have been available for more than 20 years, show a constant increase in the need for nursing care. Within two years (2013 to 2015), the number of people in need of care increased by $9 \%$ [3]. 73\% are treated on an outpatient basis, i. e. under domestic conditions, $27 \%$ are treated on an inpatient basis.

Demand is rising faster than professional personnel can be trained. More than half of the in-patients are 85+ years old [4]. The high proportion of restricted everyday competence (dementia) of $42 \%$ points to the problems and the effort in care [3].

It can be seen from Table 5 that we have a doubling of the care coefficients (per 100,000 of the age group) and the rate (share in\%) of each higher age group. After all, $53.5 \%$ of the $90+$ year old men and $69.9 \%$ of the $90+$ year old women are in need of care.

We can make a cut in the age group of the 65-74-year-olds and older. The younger age group still shows moderate rates of need for care, while a continuous and drastic deterioration of the health situation leads to a dramatic increase in the need for care during the $75+$ years. 
What does the statistics on accidents, violence and self-harm tell us about the accidents (external causes) of senior citizens [11]? Deadly injuries in men occur on average 50 times per 100,000 of the male population across all age groups. Half of the 20,513 fatal injuries among men in 2015 were caused by seniors $65+(n=10,811)$, which is three times the average for all age groups (Table 6).

In each higher age group, the risk of a fatal accident increases, be it in road traffic or in the form of a domestic accident. Fatal accidents are less common among female seniors of all ages. Fatal accidents (V01-X59) (excluding falls, drowning, suffocation, fire and flames, suicide, assault) have risen from 5,491 to 7,695 among seniors in the years 2010 to 2015 , representing $+34 \%$. This increase is significantly higher than that of $19 \%$ across all age groups (Table 7 ). In the age group of senior citizens aged $90+$, fatal accidents rose by $80 \%$ and in the $85-89$ year olds by $40 \%$.

We see the same age-related increases in the suicides of men when comparing the years 2010 to 2015 [11] (Table 8). However, the extreme increase in suicides among 90+-year-old men from 60 to 114 per 100,000 men $90+$ within 5 years should be questioned as to its validity. $\mathrm{WHO}$ and EU-wide prevention programs to reduce suicide mortality and accident mortality do not seem to be working well for seniors.

The mortality statistics also provide information on the health situation, even if the validity of the data is questioned due to insufficient coding. Of the 449,512 deaths among men in 2015, 357,951 were attributable to men $65+$, i. e. $80 \%$ of all deaths (Table 9) [12]. As a result, $20 \%$ of deaths are considered premature (aged 0-64) deaths, which are often preventable.

While the proportion of the deceased in the age group of men aged $65-69$ is $1.8 \%$, which is almost twice as high as the death rate of women, the death rate is steadily rising to reach $14.1 \%$ for men aged $85-89$ compared with $10.9 \%$ for women (Table 9 ). It is difficult to explain why death rates are higher in all age groups of male seniors than among female senior citizens. It can be assumed that the risk factors in the younger age groups of the men still exist or persist and thus have an impact on the acceleration of the mortality rates. The epidemiological analysis of the effect of risk factors on burden of disease can be calculated. This also makes it possible to compare the state of health up to the point of mortality with other countries

\section{Lessons}

1. It is not enough to have the $60+$ age group as a collective group (open to the top) in official statistics and health surveys. Life expectancy for men will also reach the limit of 80 years. This will require consideration of 5-year age groups up to $100+$ in the future.

2. The RKI's health surveys show that in the age group of men aged $65+56 \%$ is considered to be in a very good or good state of health. According to the present analysis of official data, this applies only to the age group of 65-74-year-old men.

3. Rates of hospital treatment are steadily increasing up to $90 \%$ among male seniors $90+$. This is certainly a sign of a bad health condition. Surgeries decrease with the 90+-year-old men, which means for a large proportion of hospital treatments due to the increasing loss of organ functions, geriatric and palliative care. 4. The number of severely disabled men and women aged $75+$ is around 2.5 million and 65-74 year olds around 1.7 million. This means that after the 75. year of age, a further increase in severely handicapped people occurs as a sign of deterioration in their health. At $2,371,840$ persons, the number of people in need of care is $65+$ less than the number of severely handicapped persons, of whom around 2 million are aged $75+$ and therefore, as expected, have such a poor state of health that they can no longer look after themselves alone. A new procedure for classifying the need for care will lead to a further increase in the number of people in need of care after the reform in 2017.

5. Accidents and suicides among senior citizens have not been reduced since 2010. Accident mortality rates for senior men are three times higher than the average (Table 6) and they are higher in all age groups of male seniors than in female seniors. If we look at road accidents and some groups such as death by fire, poisoning, exposure to natural forces (Table 7) we see a significant increase in fatal accidents. The question arises of a strategy for the prevention of accidents among senior citizens, which should refer to participants in traffic and victims of accidents.

6. Mortality should be carefully analyzed annually. The uncommented rate that mortality increased by $6.5 \%$ in 2015 compared to the previous year [12-15] is not sufficient for an assessment of possible health problems in the population. But it is recognizable that there are also signs of an increase in mortality among the elderly, e. g. in accidents, suicide, possibly also in diabetes (not always coded as the cause of death, possibly with under-reporting).

\section{Messages}

1. An improvement in the health situation of seniors $65+$ cannot be deduced from the available statistics. The assessment of the health situation of seniors should not be made on a flat-rate basis for $65+$-year-olds, but rather staggered according to 5 -year age groups or summed up for the age groups 65-74, 75-84,85-94 and 95 plus as minimum scaling.

2. Prevention programs for health promotion, accident prevention and suicide for the elderly should be looked at and evaluated. Safety in traffic as drivers and road users should be relevant up to an advanced age.

\section{References}

1. Bardehle D (2015) Subjective health and burden of disease of seniors. (Subjektive Gesundheit und Krankheitslast von Senioren). Urologist (Urologe) 54:1717-1724

2. Federal Statistical Office Germany (Destatis): Population of Germany up to 2060 Results of the 13. Coordinated population pre-calculation for Germany 2015. Koordinierte Bevölkerungsvorausberechnung für Deutschland bis zum Jahr 2060, www.destatis.de.

3. Federal Statistical Office Germany (Deatatis) (2015) Care Statistics - Care within the framework of long-term care insurance 2015. www.destatis.de.

4. Federal Statistical Office Germany (Destatis) (2016) Elderly People in Germany and in the European Union 2016. Ältere Menschen in Deutschland und der Europäischen Union (EU) 2016. www.destatis.de/publikationen/themat

5. Foundation of Men's Health Berlin (Ed.) Sexuality of Men. Third Men's Health Report of Germany. Psychosozial 2017: 450

6. Robert Koch-Institute (RKI) (2016) Center for Cancer Registry data. Report on Cancer in 'Germany 2016. Zentrum für Krebsregisterdaten. Bericht zum Krebsgeschehen in Deutschland. www.krebsdaten.de/krebs

7. Federal Statistical Office Germany: Statistical Yearbook Germany (2015) Population and Demography. Statistisches Jahrbuch Deutschland. Bevölkerung und Demographie. www.destatis.de/publikationen.

8. 8. Federal Statistical Office Germany (Destatis) (2015) Hospital Discharge Statistics Diagnosedaten der Patienten in Krankenhäusern. www.destatis.de.

9. Federal Statistical Office Germany (Destatis) (2015) Operations and Procedures of inpatient persons in 2015. Vollstationäre Patienten in Krankenhäusern. Operationen und Prozeduren. www.destatis.de.

10. Federal Statistical Office Germany (Destatis) (2015) Statistics of the Severely Disabled Persons at 31.12.2015. www.destatis.de. 
11. Federal Statistical Office Germany (Destatis) (2015) Accidents, Violence, Self-harm. (Unfälle, Gewalt, Selbstverletzungen). www.destatis.de.

12. Federal Statistical Office Germany (Destatis) (2016) Causes of death in Germany 2016 Todesursachen in Deutschland 2016. www.destatis.de/publikationen/themat

13. Institute of Health Metrics and Evaluation (IHME) USA: Global Burden of Disease (GBD). www.healthdata.org/gbd
14. Federal Statistical Office Germany (Destatis): Demographic change in Germany issue 2 - Effects on hospital treatment and those in need of care 2010. Demografischer Wandel in Deutschland - Heft 2 - Auswirkungen auf Krankenhausbehandlungen und Pflegebedürftige 2010. www.destatis.de/publikationen/themat

15. Bardehle D (2017) Sexual Health of Men. (Sexuelle Gesundheit von Männern) Economic magazine for the urologist. Wirtschaftsmagazin für den Urologen 3: 37-40

Copyright: $(02017$ Bardehle D. This is an open-access article distributed under the terms of the Creative Commons Attribution License, which permits unrestricted use, distribution, and reproduction in any medium, provided the original author and source are credited. 